\title{
First laser ions at the CERN-MEDICIS facility
}

Check for updates

Vadim Maratovich Gadelshin ${ }^{1,2}$. Shane Wilkins ${ }^{3}$. Valentin Nikolaevich Fedosseev ${ }^{3}$. Ermanno Barbero ${ }^{3}$. Vincent Barozier ${ }^{3}$. Ana-Paula Bernardes ${ }^{3}$. Eric Chevallay ${ }^{3}$. Thomas Elias Cocolios ${ }^{4}$ - Bernard Crepieux ${ }^{3}$ - Kristof Dockx ${ }^{4}$. Matthias Eck ${ }^{1}$. Pascale Fernier $^{3} \cdot$ Roberto Formento Cavaier $^{5}$. Ferid Haddad ${ }^{6,7}$. Johannes Jakobi ${ }^{1}$. Laura Lambert ${ }^{3}$. Bruce Allan Marsh ${ }^{3}$. Stefano Marzari ${ }^{3}$. Joao Pedro Ramos Ma $^{3,4}$ Annie Ringvall Moberg ${ }^{3,8}$. Sebastian Rothe ${ }^{3}$. Thierry Stora ${ }^{3}$. Dominik Studer ${ }^{1}$. Andres Vieitez Suarez ${ }^{3} \cdot$ Felix Weber $^{1} \cdot$ Klaus Wendt $^{1} \cdot$ MEDICIS Collaboration $^{2}$

Published online: 6 May 2020

(C) The Author(s) 2020

\begin{abstract}
The CERN-MEDICIS facility aims to produce emerging medical radionuclides for the theranostics approach in nuclear medicine with mass separation of ion beams. To enhance the radioisotope yield and purity of collected samples, the resonance ionization laser ion source MELISSA was constructed, and provided the first laser ions at the facility in 2019. Several operational tests were accomplished to investigate its performance in preparation for the upcoming production of terbium radioisotopes, which are of particular interest for medical applications.
\end{abstract}

Keywords CERN MEDICIS · Isotope separation · Radioactive ion beam · Laser resonance ionization $\cdot$ Nuclear medicine $\cdot$ Theranostics $\cdot$ Terbium

This article is part of the Topical Collection on Proceedings of PLATAN 2019, 1st International Conference, Merger of the Poznan Meeting on Lasers and Trapping Devices in Atomic Nuclei Research and the International Conference on Laser Probing, Mainz, Germany 19-24 May 2019

Edited by Krassimira Marinova, Michael Block, Klaus D.A. Wendt and Magdalena Kowalska

Vadim Maratovich Gadelshin

gadelshinvm@mail.ru

1 Institut für Physik, Johannes Gutenberg-Universität, 55128 Mainz, Germany

2 Institute of Physics and Technology, Ural Federal University, 620002 Yekaterinburg, Russia

3 EN Department, CERN, 1211 Geneva, Switzerland

4 Instituut voor Kern- en Stralingsfysica, KU Leuven, 3001 Leuven, Belgium

5 Advanced Accelerator Applications, A Novartis Company, 10010 Colleretto Giacosa/Ivrea, Italy

6 GIP ARRONAX, Nantes, France

7 SUBATECH, Nantes University, Nantes, France

8 Gothenburg University, Gothenburg, Sweden 


\section{Introduction}

The MEDICIS project (MEDical Isotopes Collected from ISOLDE) is devoted to the production of a broad range of non-conventional radionuclides, which have a great potential for nuclear medicine [1]. The dedicated CERN-MEDICIS radioactive ion beam facility was constructed adjacent to CERN-ISOLDE, and exploits similar operation principles for the extraction and purification of radioisotopes samples, based on electromagnetic mass separation [2]. The MEDICIS facility can either work in a parasitic mode of ISOLDE, by using the remaining part of the proton beam, which did not interact with ISOLDE target [3], or process irradiated materials from other facilities, like ILL (Grenoble, France), GIP Arronax (Nantes, France), etc.

Terbium ( $\mathrm{Tb}$ ) is the only element in Mendeleev's periodic table, which possesses four complementary medically relevant radioisotopes that appear to be well suited for the theranostics approach [4]. Specifically, ${ }^{149} \mathrm{~Tb}$ is a promising radionuclide for $\alpha$-therapy [5, 6]; ${ }^{152} \mathrm{~Tb}$ and ${ }^{155} \mathrm{~Tb}$ can be used for PET and SPECT imaging, respectively [7, 8]; and ${ }^{161} \mathrm{~Tb}$ is appropriate for $\beta^{-}$-therapy [9]. With the exception of ${ }^{161} \mathrm{~Tb}$ (which can be produced via the ${ }^{160} \mathrm{Gd}(\mathrm{n}, \gamma){ }^{161} \mathrm{Gd} \rightarrow{ }^{161} \mathrm{~Tb}$ reaction at a nuclear reactor), the aforementioned isotopes can be generated through spallation process $\mathrm{Ta}(\mathrm{p}, \mathrm{x}) \mathrm{Tb}$ or irradiating a gadolinium $(\mathrm{Gd})$ target at an accelerator [10].

The production of $\mathrm{Tb}$ radioisotopes is accompanied by isobaric as well as isotopic contamination, which cannot be removed by the standard radiochemical techniques. Mass separation is mandatory to provide a pure product along with the required specific activity of a radionuclide. However, the MEDICIS electromagnetic mass separator is unable to separate isobars. For instance, it was demonstrated that ${ }^{139} \mathrm{Ce}^{16} \mathrm{O}$ was present during the extraction of ${ }^{155} \mathrm{~Tb}$, produced at ISOLDE by irradiation of a tantalum target with high energy proton beam. ${ }^{139} \mathrm{Ce}^{16} \mathrm{O}$ is a thermally ionized isobaric contaminant and is not separated from ${ }^{155} \mathrm{~Tb}$ in the electromagnet. The same concern exists for other stable (e.g. ${ }^{139} \mathrm{La}^{16} \mathrm{O},{ }^{155} \mathrm{Gd}$ ) or radioactive $\left({ }^{155} \mathrm{Eu}\right)$ impurities [11]. Similar conditions were observed for the shorter-lived isotope ${ }^{149} \mathrm{~Tb}$, also produced at ISOLDE, where isobaric contaminants ${ }^{149} \mathrm{Eu}$ and ${ }^{133} \mathrm{Ce}^{16} \mathrm{O}$ are limiting the sample purity [12]. Furthermore, the separation technique was developed to extract minute quantities of radioisotopes. The question remains if the technique, in its current form, can cope with high throughput, being necessary to provide a large-scale production of $\mathrm{Tb}$ radioisotopes. The use of thermal ionization only achieves a few percent for the overall separation efficiency [13], hampering the collection of a medically sufficient amount of radionuclides.

The use of a resonance ionization laser ion source [14] in combination with electromagnetic mass separation allows to improve the ion beam purity by specifically enhancing the ionization efficiency of the desired element. This technique utilises multiple lasers precisely tuned to transitions between atomic energy levels to stepwise excite and ionize isotopes of the element of interest [15]. Subsequently, the element-selective ionization process reduces the impact of any isobaric contaminants, assisting to achieve a high specific activity [16]. Efficiencies in the tens of percent range are commonly achieved with the laser ion source so that, when applicable, this is an effective means of maximising the overall radioisotope yield [17]. This unrivalled combination of element selectivity and high ionization efficiency made laser ion sources commonplace at radioactive ion beam facilities worldwide [18]. Construction works on the MEDICIS Laser Ion Source for Separator Assembly (MELISSA) was completed in 2019. Here a report on delivery of the first laser ions at the CERN-MEDICIS facility will be presented. 


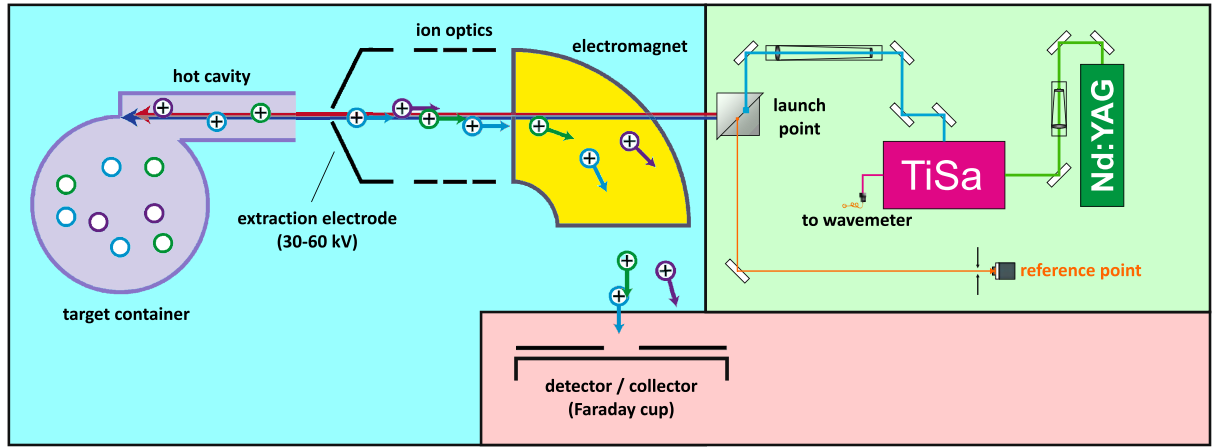

Radiochemical Lab

Fig. 1 MEDICIS Separator Assembly Layout

\section{Experimental setup}

The MEDICIS Separator consists of a target-ion source assembly, ion extraction system and a 55-degree double focusing magnet with a bending radius of $1.5 \mathrm{~m}$ providing a mass resolving power of around 400, all of which are enclosed in the Mass Separator Bunker [19]. The radioisotope collector is located in the Radiochemical Laboratory. The MELISSA Laser Lab hosts the laser installation required for the operation of the laser ion source (Fig. 1). Preliminary irradiated target materials or samples containing radioactive isotopes of interest are enclosed in a target container, which is connected to a hot cavity ion source through a transfer line. The container and ion source cavity can be independently heated to temperatures of $2000-2500^{\circ} \mathrm{C}$. This is necessary for the temperature-dependent release process of atoms from the target container into the cavity [20]. The atoms are then ionized via the element-selective laser ionization process. The resulting ions are extracted by up to $60 \mathrm{kV}$ accelerating potential, focused by ion optics, separated by their mass-to-charge ratio in the dipole electromagnet, and guided towards the collector. Finally, only the desired radioisotope should be collected.

A quantified stable Tb sample with $2 \times 10^{17}$ atoms (50 $\mu$ l of an AAS standard solution from Alfa Aesar) was placed inside the target container. For the measurement, a target unit $(675 \mathrm{M})$ with rhenium hot cavity ion source was operated, which was used before for tests of the $\mathrm{Tb}$ production yield only with surface ionization. $\mathrm{As} \mathrm{Tb}$ radioisotopes will be produced by irradiation of a Gd target material [10], the presence of a macroscopic amount of Gd from previous tests in the target container will help to simulate the anticipated operating conditions.

A detailed description of the MELISSA setup is presented in [21]. In brief, it comprises an all-solid-state laser system, based on Ti:Sapphire lasers developed at Mainz University [22]. To demonstrate the operation of MELISSA, a simplified two-step single-colour laser resonance ionization scheme for $\mathrm{Tb}$ was used, which is shown in Fig. 2. It was developed at Mainz University during laser spectroscopic investigations of the $\mathrm{Tb}$ atomic structure (details on the Tb laser spectroscopy will be published separately [23]). The excitation scheme begins from the thermally populated state $462.08 \mathrm{~cm}^{-1}$, and, through the excited state at $25076.26 \mathrm{~cm}^{-1}[24,25]$, it leads to the auto-ionizing state of $49690.15 \mathrm{~cm}^{-1}$. 

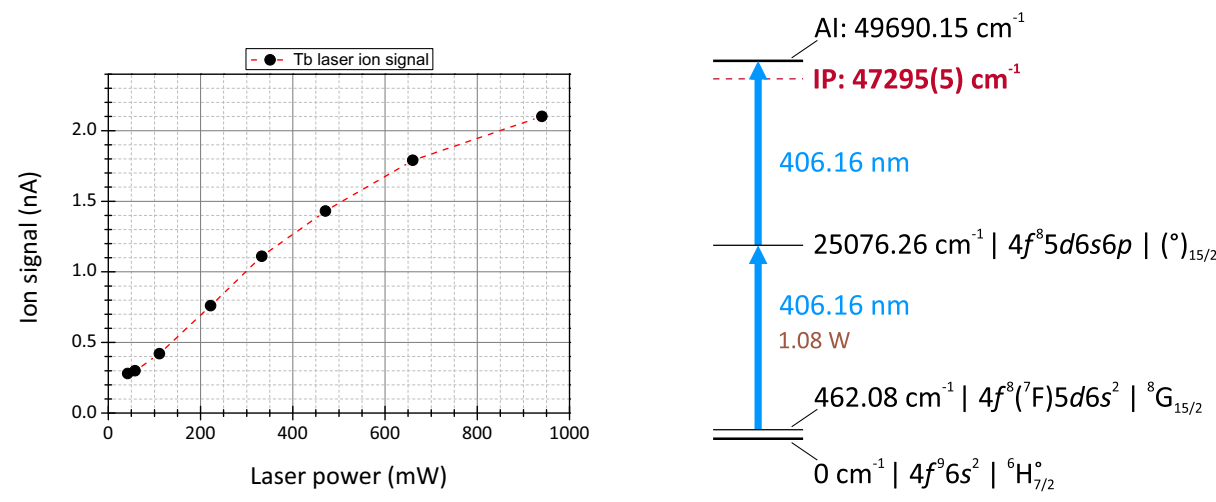

Fig. 2 A two-step single-colour laser resonance ionization scheme for terbium (right) and its saturation curve (left). The laser power was measured directly at the output of the Ti:Sapphire laser

A single-colour ionization scheme is remarkably convenient for commissioning, because the relative timing between laser pulses and their spatial overlap do not need to be considered, compared to most ionization schemes that require 2-3 different laser beams. For the measurement, one standard " $Z$ " cavity Ti:Sapphire laser was used, pumped by $8 \mathrm{~W}$ of output power from an InnoLas Nanio 532-18-Y laser. The required 406-nm laser light was produced via intra-cavity frequency doubling [26], providing up to $1.1 \mathrm{~W}$ of output power. The transport efficiency of the optical path was measured to be approximately $70 \%$ from the laser lab to the entrance window of the mass separator. The measurement of this value up to the hot cavity is difficult; but as the separator window is of high quality and uncoated, and there are no further optical elements between the window and the ion source, and the laser beam spot size in the separator is less than $3 \mathrm{~mm}$, the losses between the window and the hot cavity can be neglected.

\section{Results and discussion}

The first laser ions provided by MELISSA were measured on 24th April 2019. Several operational tests were performed to characterize the laser ion source, and to localize possible weaknesses. The rhenium ion source was operated at a constant temperature of $2270^{\circ} \mathrm{C}$ during all measurements.

The performance of the resonance ionization scheme at different target temperatures is shown in Fig. 3. One can clearly see that laser ionization has increased the ion signal of $\mathrm{Tb}$ by a factor of 15 (target container temperature of $1480^{\circ} \mathrm{C}$ ), as given by the ratio between "laser ON" and "laser OFF" mode (laser+surface vs. only surface ionization). At higher operating temperatures, the enhancement factor decreases due to the increased overall surface ionization rate. An enhancement factor of 7 was seen even at the highest operating temperature tested $\left(2025^{\circ} \mathrm{C}\right)$.

Naturally, the total ion current (measured without lasers) is also significantly increased at the maximal temperature. The presence of an excess of ions in the hot cavity can cause a space-charge effect, which will influence the overall performance of the separator assembly. It is observed that, when a total ion current exceeds $100 \mathrm{nA}$, the ion source efficiency begins to decrease. Therefore, the effect of sample outgassing and a consequential excess of ions in the hot cavity must be taken into account, when the mass separator operation is optimized 


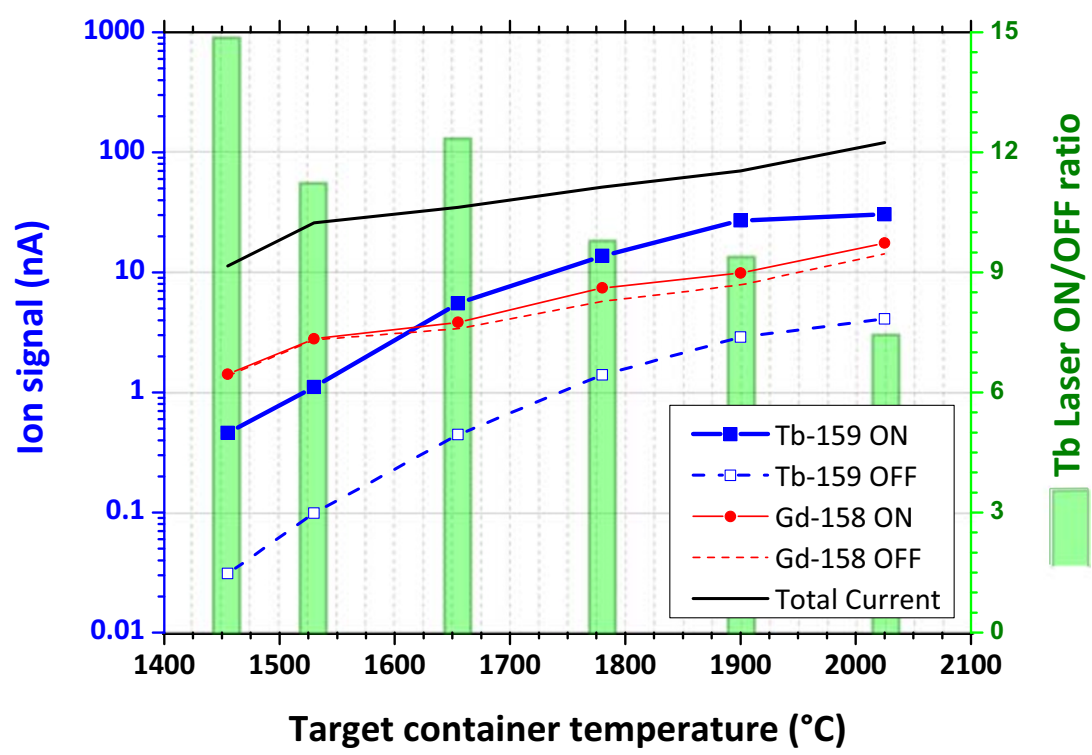

Fig. 3 Ion signal behaviour for different target container temperatures measured at different masses (158 and $159 \mathrm{u}$ ) with lasers switched $\mathrm{ON}$ and OFF. The rhenium ion source was operated at $2270^{\circ} \mathrm{C}$. The total ion current does not include a contribution from laser ions as the Faraday cup, used during this measurement, blocks the laser beam path to the source

to achieve the maximum extraction efficiency for the isotope of interest. That should be considered in future ion source development program.

From the behaviour of the Gd signal (measured at mass $158 \mathrm{u}$, which represents the most abundant (25\%) natural ${ }^{158} \mathrm{Gd}$ isotope), it can be stated that the laser scheme is sufficiently element-selective. The laser influence increased the Gd ion signal by less than a factor of 1.3 , possibly caused by a nearby resonance in the Gd spectrum. As the real Tb sample will be produced from a Gd target, it is important to ensure that there will be no detrimental interference during a Tb collection, namely for ${ }^{152} \mathrm{~Tb}$ and ${ }^{155} \mathrm{~Tb}$. As this test was conducted with a previously used target unit, the relative amounts of $\mathrm{Gd}$ and $\mathrm{Tb}$ atoms in the target container were not possible to quantify. In the real target, the surplus of atomic Gd components is expected to be several orders of magnitude higher than that of $\mathrm{Tb}$. Moreover, in production conditions for $\mathrm{Tb}$ radioisotope collection, a two-step two-colour ionization scheme, developed at Mainz University, will be used, which demonstrated better ionization performance and selectivity than the one used in this work [23]. On the other hand, the presence of a bulk amount of Gd is still an issue, because in this case the surface-ionized Gd signal can be comparable, if not superior, to the Tb laser ion signal. The preliminary solution is a pre-purification of the irradiated target material to reduce the $\mathrm{Gd}: \mathrm{Tb}$ ratio to a tolerable level.

The mass spectra in the region of interest, shown in Fig. 4, look promising: the mass peaks are well-resolved and do not interfere with each other. The ${ }^{159} \mathrm{TbO}^{+}$molecular ion does not appear in a significant amount, confirming the expected chemical behaviour of the Tb sample. The ion source behaviour, when coupled to the real Gd target used for radioisotope extraction, may differ from that of these tests due to differences in sample outgassing, neutral atom density and composition, and overall ion throughput, and should be considered additionally. 


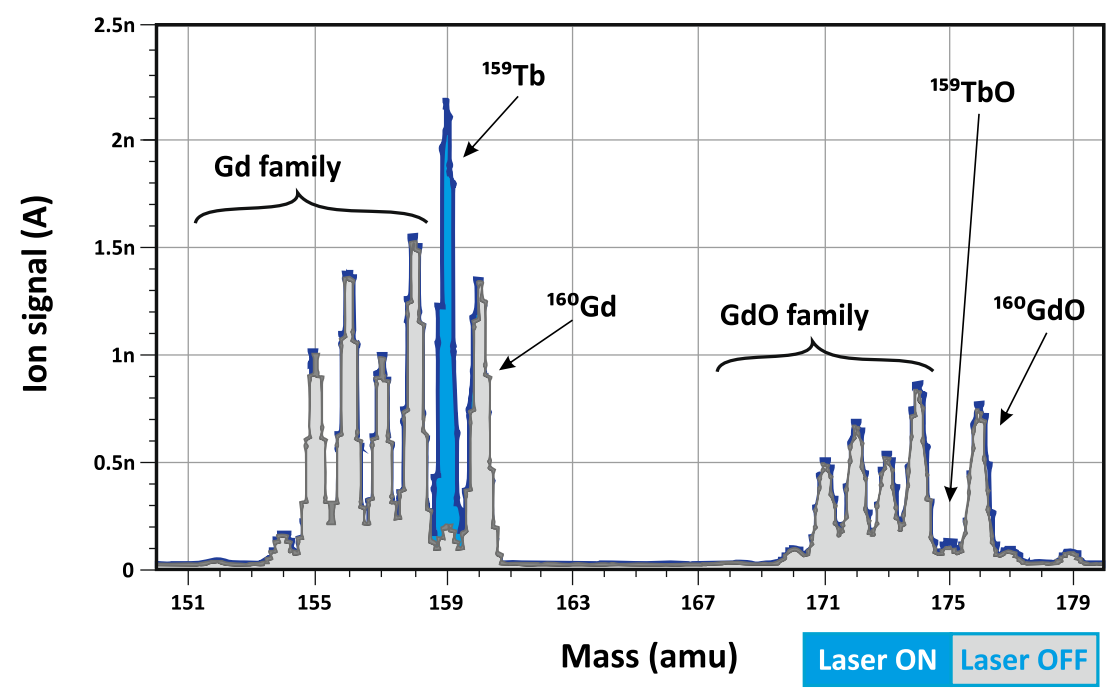

Fig. 4 Mass spectra in the region of terbium and gadolinium isotopes and their oxide sidebands, obtained with and without lasers

A further test was performed assessing the impact of the laser repetition rate on the $\mathrm{Tb}$ ion signal. The simplified two-step single-colour laser resonance ionization scheme is ideal for this measurement. Typically, atoms effuse through the hot cavity within $100 \mu \mathrm{s}$ [27, 28], which corresponds to at least one interaction with laser pulses at $10 \mathrm{kHz}$ repetition rate. By raising the laser repetition rate beyond this value, the number of interactions can be increased, potentially leading to a higher ion signal regardless of atom residence time in the cavity, as the laser ionisation efficiency is likely less than $100 \%$ even if all transitions are saturated. The pump laser pulse energy was kept constant at $0.8 \mathrm{~mJ}$, what will make this study valid and independent from a saturation degree of the used scheme (which was not saturated, Fig. 2). Conclusive measurements were performed up to $16 \mathrm{kHz}$, as further increase in the repetition rate induced damage to the Ti:Sapphire crystal.

Results can be found in Table 1. It can be stated that the expected growth of the ion signal is observed. It was being primarily dependent on the growth of Ti:Sapphire average output power, not directly proportional to the pump laser power. At the same time, the pulse energy of the Ti:Sapphire laser was decreased almost by $20 \%$. It means that, even though the atoms saw more pulses, each pulse had a lower probability of causing ionization. The reduction of the ion signal, normalized to the Ti:Sapphire laser power, at higher repetition rates confirms this conclusion.

Nevertheless, the increase of the ion signal was observed. And it can be expected that the bigger growth will be achieved, if the Ti:Sapphire laser is adapted to operate at a higher repetition rate without losses of the output pulse energy. On the other hand, it has to be compromised with an associated risk of an optics damage due to the increased total intracavity power. The increase of the ion signal could be even higher, if the mean residence time of atoms in the hot cavity is less than the time between laser pulses $(100 \mu \mathrm{s}$ at $10 \mathrm{kHz})$. For instance, if the atom residence time is $50 \mu \mathrm{s}$, a 2-fold ionization improvement can be expected for a system with $20 \mathrm{kHz}$ repetition rate and the same pulse energy.

Still more tests and development with representative isotope production samples and targets are required to optimize operation and sample handling procedures to achieve the 
Table 1 The signal behaviour test for different repetition rates of the pump laser

\begin{tabular}{llllll}
\hline $\begin{array}{l}\text { Repeti- } \\
\text { tion rate } \\
(\mathrm{kHz})\end{array}$ & $\begin{array}{l}\text { Pump } \\
\text { laser power } \\
(\mathrm{W})\end{array}$ & $\begin{array}{l}\text { Ti:Sa laser } \\
\text { power } \\
(\mathrm{W})\end{array}$ & $\begin{array}{l}\text { Ti:Sa laser } \\
\text { pulse energy } \\
(\mu \mathrm{J})\end{array}$ & $\begin{array}{l}\text { Laser ion } \\
\text { signal } \\
(\mathrm{nA})\end{array}$ & $\begin{array}{l}\text { Laser ions / } \\
\text { Ti:Sa power } \\
(\mathrm{nA} / \mathrm{W})\end{array}$ \\
\hline 10 & 8.01 & 1.08 & 108 & 1.77 & 1.64 \\
12 & 9.59 & 1.20 & 100 & 1.98 & 1.65 \\
14 & 11.21 & 1.24 & 88.6 & 2.03 & 1.64 \\
16 & 12.80 & 1.43 & 89.4 & 2.28 & 1.59 \\
18 & 14.35 & - & - & - & - \\
\hline
\end{tabular}

The background ion signal was constant at $0.24 \mathrm{nA}$ during the whole measurement. The laser ion signal is calculated by subtracting the background from the measured ion signal

required throughput and purity of collected nuclides. It concerns not only acceleratorgenerated radioisotopes, like $\mathrm{Tb} / \mathrm{Gd}$ cross-contamination considered in this work, but also nuclides generated at nuclear reactors, for instance ${ }^{169} \mathrm{Er}$ with an isotopic ${ }^{168} \mathrm{Er}$ interference from the target material [13]. In this case, both isotopes will be efficiently ionized by an element-selective ionization. These situations can cause a significant reduction in the separation efficiency due to the aforementioned high total current. Resolving such problems could be possible by applying an isotope-selective ionization scheme (e.g. for ${ }^{169} \mathrm{Er}$ ) or by developing an ion source configuration, which should be adapted for a high ion flux operation, e.g. [29].

\section{Summary and outlook}

The resonance ionization laser ion source MELISSA is now in operation and has successfully delivered the first laser ions at the CERN-MEDICIS facility. Stable ${ }^{159} \mathrm{~Tb}$ laser ions were produced using a simplified 2-step single-colour laser resonance ionization scheme. The laser enhancement ratio was investigated over a range of typical operating temperatures promising at least a factor of 7 improvement in efficiency over surface ionization only. The simplified nature of the resonance ionization scheme allowed the effect of the laser repetition rate on the ionization efficiency to be investigated.

Presently, the CERN proton accelerator complex is shutdown and will restart in 2021. During the year 2020, MEDICIS will nevertheless perform separation of $\mathrm{Tb}$ radioisotopes from externally irradiated Gd targets. As both elements, $\mathrm{Tb}$ and $\mathrm{Gd}$, have similar surface ionization efficiencies, it is important to employ an element-selective ionization process to achieve a pure radioisotopic yield in combination with the high ionization efficiency. Therewith, MELISSA will become a crucial tool for the production of pure medical radiolathanides and other relevant nuclides.

Acknowledgements Open Access funding provided by Projekt DEAL. We would like to acknowledge the help and assistance from the whole MEDICIS collaboration; from CERN-ISOLDE Technical and Physical groups. This research project has been supported by a Marie Skłodowska-Curie Innovative Training Network Fellowship of the European Commission's Horizon 2020 Programme under contract number 642889 MEDICIS-PROMED; by the German Federal Ministry of Education and Research under the consecutive projects 05P12UMCIA and 05P15UMCIA; by the Research Foundation Flanders FWO (Belgium) and by a KU Leuven START grant. 
Open Access This article is licensed under a Creative Commons Attribution 4.0 International License, which permits use, sharing, adaptation, distribution and reproduction in any medium or format, as long as you give appropriate credit to the original author(s) and the source, provide a link to the Creative Commons licence, and indicate if changes were made. The images or other third party material in this article are included in the article's Creative Commons licence, unless indicated otherwise in a credit line to the material. If material is not included in the article's Creative Commons licence and your intended use is not permitted by statutory regulation or exceeds the permitted use, you will need to obtain permission directly from the copyright holder. To view a copy of this licence, visit http://creativecommonshorg/licenses/by/4.0/.

\section{References}

1. Jonson, B.: Exotic nuclei. Her. Russ. Acad. Sci. 89(3), 221-230 (2019). https://doi.org/10.1134/ S1019331619030043

2. Catherall, R., Andreazza, W., Breitenfeldt, M., Dorsival, A., Focker, G.J., Gharsa, T.P., Giles, T.J., Grenard, J.-L., Locci, F., Martins, P., Marzari, S., Schipper, J., Shornikov, A., Stora, T.: The ISOLDE facility. J. Phys. G Nucl. Part Phys. 44(9), 094002 (2017). https://doi.org/10.1088/1361-6471/aa7eba

3. Dos Santos Augusto, R., Buehler, L., Lawson, Z., Marzari, S., Stachura, M., Stora, T.: CERNMEDICIS (Medical Isotopes Collected from ISOLDE): A new facility. Appl. Sci. 4, 265-281 (2014). https://doi.org/10.3390/app4020265

4. Mủller, C., Zhernosekov, K., Kòster, U., Johnston, K., Dorrer, H., Hohn, A., Van Der Walt, N.T., Türler, A., Schibli, R.: A unique matched quadruplet of terbium radioisotopes for PET and SPECT and for $\alpha$ - and $\beta$-radionuclide therapy: An in vivo proof-of-concept study with a new receptor-targeted folate derivative. J. Nucl. Med. 53(12), 1951-1959 (2012). https://doi.org/10.2967/jnumed.112.107540

5. Beyer, G.-J., Miederer, M., Vranjes-Duric, S., Comor, J.J., Künzi, G., Hartley, O., SenekowitschSchmidtke, R., Soloviev, D., Buchegger, F.: Targeted alpha therapy in vivo: direct evidence for single cancer cell kill using 149Tb-rituximab. Eur. J. Nucl. Med. Mol. Imaging 31(4), $547-554$ (2004). https://doi.org/10.1007/s00259-003-1413-9

6. Umbricht, C.A., Köster, U., Bernhardt, P., Gracheva, N., Johnston, K., Schibli, R., van der Meulen, N.P., Müller, C.: Alpha-PET for Prostate Cancer: Preclinical investigation using 149Tb-PSMA-617. Sci. Rep. 9(1), 17800 (2019). https://doi.org/10.1038/s41598-019-54150-w

7. Müller, C., Singh, A., Umbricht, C.A., Kulkarni, H.R., Johnston, K., Benešová, M., Senftleben, S., Müller, D., Vermeulen, C., Schibli, R., Köster, U., van der Meulen, N.P., Baum, R.P.: Preclinical investigations and first-in-human application of 152Tb-PSMA-617 for PET/CT imaging of prostate cancer. EJNMMI Res. 9(1), 68 (2019). https://doi.org/10.1186/s13550-019-0538-1

8. Mủller, C., Fischer, E., Behe, M., Kòster, U., Dorrer, H., Reber, J., Haller, S., Cohrs, S., Blanc, A., Grünberg, J., Bunka, M., Zhernosekov, K., van der Meulen, N., Johnston, K., Türler, A., Schibli, R.: Future prospects for SPECT imaging using the radiolanthanide terbium-155 - production and preclinical evaluation in tumor-bearing mice. Nucl. Med. Biol. 41(S), 58-65 (2014). https://doi.org/10.1016/j. nucmedbio.2013.11.002

9. Mủller, C., Umbricht, C.A., Gracheva, N., Tschan, V.J., Pellegrini, G., Bernhardt, P., Zeevaart, J.R., Kòster, U., Schibli, R., van der Meulen, N.P.: Terbium-161 for PSMA-targeted radionuclide therapy of prostate cancer. Eur. J. Nucl. Med. Mol. Imaging 46(9), 1919-1930 (2019). https://doi.org/10.1007/s00259-019-04345-0

10. Formento-Cavaier, R., Haddad, F., Sounalet, T., Stora, T., Zahi, I.: Terbium radionuclides for theranostics applications: A focus on MEDICIS-PROMED. Phys. Proc. 90(November 2016), 157-163 (2017). https://doi.org/10.1016/j.phpro.2017.09.053

11. Webster, B., Ivanov, P., Russell, B., Collins, S., Stora, T., Ramos, J.P., Kòster, U., Robinson, A.P., Read, D.: Chemical purification of terbium-155 from pseudo-isobaric impurities in a mass separated source produced at CERN. Sci. Rep. 9(1), 1-9 (2019). https://doi.org/10.1038/s41598-019-47463-3

12. Kreim, S., Atanasov, D., Beck, D., Blaum, K., Böhm, C., Borgmann, C., Breitenfeldt, M., Cocolios, T., Fink, D., George, S., Herlert, A., Kellerbauer, A., Köster, U., Kowalska, M., Lunney, D., Manea, V., Minaya Ramirez, E., Naimi, S., Neidherr, D., Nicol, T., Rossel, R., Rosenbusch, M., Schweikhard, L., Stanja, J., Wienholtz, F., Wolf, R., Zuber, K.: Recent exploits of the ISOLTRAP mass spectrometer. Nucl. Instrum. Methods Phys. Res. Section B: Beam Int. Mater. Atoms 317, $492-500$ (2013). https://doi.org/10.1016/j.nimb.2013.07.072

13. Formento-Cavaier, R., Köster, U., Crepieux, B., Gadelshin, V., Haddad, F., Stora, T., Wendt, K.: Very high specific activity erbium 169Er production for potential receptor-targeted radiotherapy. 
Nucl. Instrum. Methods Phys. Res. Section B: Beam Int. Mater. Atoms 463, 468-471 (2020). https://doi.org/10.1016/j.nimb.2019.04.022

14. Mishin, V., Fedoseyev, V., Kluge, H.-J., Letokhov, V., Ravn, H., Scheerer, F., Shirakabe, Y., Sundell, S., Tengblad, O.: Chemically selective laser ion-source for the CERN-ISOLDE on-line mass separator facility. Nucl. Instrum. Methods Phys. Res. Section B: Beam Int. Mater. Atoms 73(4), 550-560 (1993). https://doi.org/10.1016/0168-583X(93)95839-W

15. Letokhov, V.: Laser photoionization spectroscopy. Academic Press, Orlando (1987)

16. Kieck, T., Dorrer, H., Düllmann, C.E., Gadelshin, V., Schneider, F., Wendt, K.: Highly efficient isotope separation and ion implantation of $163 \mathrm{Ho}$ for the ECHo project. Nucl Instrum Methods Phys Res Section A: Accelerators, Spectrometers, Detectors and Associated Equipment 945, 162602 (2019). https://doi.org/10.1016/j.nima.2019.162602

17. Gadelshin, V.M., Heinke, R., Kieck, T., Kron, T., Naubereit, P., Rösch, F., Stora, T., Studer, D., Wendt, K.: Measurement of the laser resonance ionization efficiency for lutetium. Radiochimica Acta 107(7), 653-661 (2019). https://doi.org/10.1515/ract-2019-3118

18. Fedosseev, V.N., Kudryavtsev, Y., Mishin, V.I.: Resonance laser ionization of atoms for nuclear physics. Physica Scripta 85(5), 058104 (2012). https://doi.org/10.1088/0031-8949/85/05/058104

19. Martinez Palenzuela, Y.: Characterization and optimization of a versatile laser and electron-impact ion source for radioactive ion beam production at ISOLDE and MEDICIS, Phd thesis, KU Leuven (2019)

20. Kirchner, R.: On the release and ionization efficiency of catcher-ion-source systems in isotope separation on-line. Nucl. Instrum. Methods Phys. Res. Section B: Beam Int. Mater. Atoms 70(1-4), 186-199 (1992). https://doi.org/10.1016/0168-583X(92)95930-P

21. Gadelshin, V., Barozier, V., Cocolios, T., Fedosseev, V., Formento-Cavaier, R., Haddad, F., Marsh, B., Marzari, S., Rothe, S., Stora, T., Studer, D., Weber, F., Wendt, K.: MELISSA: Laser ion source setup at CERN-MEDICIS facility. Blueprint. Nucl. Instrum. Methods Phys. Res. Section B: Beam Int. Mater. Atoms 463, 460-463 (2020). https://doi.org/10.1016/j.nimb.2019.04.024

22. Kron, T.: Pushing the limits of resonance ionization mass spectrometry. Ionization Efficiency in Palladium and Spectral Resolution in Technetium. Johannes Gutenberg-Universitat Mainz, Phd thesis (2016)

23. Gadelshin, V., Heinke, R., Studer, D., Wendt, K.: Terbium laser resonance ionization scheme development (in preparation)

24. Ralchenko, J.Y., Kramida, A.E.: Reader, NIST Atomic Spectra Database (ver. 5.7.1). https://doi.org/10. 18434/T4W30F. https://www.nist.gov/pml/atomic-spectra-database (2019)

25. Martin, W.C., Zalubas, R., Hagan, L.: Atomic energy levels, - the rare-earth elements, Tech. rep., National Bureau of Standards, Gaithersburg, MD. https://doi.org/10.6028/NBS.NSRDS.60 (1978)

26. Sonnenschein, V., Moore, I.D., Pohjalainen, I., Reponen, M., Rothe, S., Wendt, K.: Intracavity frequency doubling and difference frequency mixing for pulsed ns Ti:Sapphire laser systems at on-line radioactive ion beam facilities. In: Proceedings of the conference on advances in radioactive isotope science (ARIS2014), Journal of the physical society of Japan (2015). https://doi.org/10.7566/JPSCP.6.030126

27. Fedosseev, V., Huber, G., Köster, U., Lettry, J., Mishin, V., Ravn, H., Sebastian, V.: The ISOLDE laser ion source for exotic nuclei. Hyperfine Interact. 127(1-4), 409-416 (2000). https://doi.org/10.1023/A: 1012609515865

28. Turek, M.: Surface ionization of radioactive nuclides - Numerical simulations. Acta Phys. Pol. A 123(5), 847-850 (2013). https://doi.org/10.12693/APhysPolA.123.847

29. Martinez Palenzuela, Y., Marsh, B., Ballof, J., Catherall, R., Chrysalidis, K., Cocolios, T., Crepieux, B., Day Goodacre, T., Fedosseev, V., Huyse, M., Larmonier, P., Ramos, J., Rothe, S., Smith, J., Stora, T., Van Duppen, P., Wilkins, S.: Enhancing the extraction of laser-ionized beams from an arc discharge ion source volume. Nucl. Instrum. Methods Phys. Res. Section B: Beam Int. Mater. Atoms 431, 59-66 (2018). https://doi.org/10.1016/j.nimb.2018.06.006

Publisher's note Springer Nature remains neutral with regard to jurisdictional claims in published maps and institutional affiliations. 